\title{
Postoperative chylothorax
}

\author{
May Al-Sahaf \\ Department of Cardiothoracic Surgery, Hammersmith Hospital, Imperial College Healthcare NHS Trust, London, UK \\ Correspondence to: Miss May Al-Sahaf. Consultant Thoracic Surgeon, Imperial College Healthcare NHS Trust, Hammersmith Hospital, Department \\ of Cardiothoracic Surgery, Du Cane Road, London W12 0HS, UK. Email: may.alsahaf@nhs.net.
}

\begin{abstract}
Fortunately, the incidence of postoperative chylothorax is low. Postoperative chylothorax can result from iatrogenic injury to either the thoracic duct or its tributaries during thoracic procedures. Thoracic duct injury has been reported following several thoracic procedures including oesophagectomy, pulmonary resections, mediastinal lymph node dissection and aortic surgery. Knowledge of the anatomical course and variations in ductal anatomy reduces the risks of injury during surgery. Chylothorax results in metabolic derangement, hypovolaemia, acidosis, malnutrition and immunosuppression. Undiagnosed, postoperative chylothorax could have devastating effects with significant morbidity and a mortality of up to $30 \%$. Early diagnosis is therefore imperative to enable prompt and aggressive management. If postoperative chylothorax is suspected, it should be immediately investigated to confirm the diagnosis. Familiarity with the diagnostic and management procedures are therefore important to help reduce the complications of postoperative chylothorax. There are several options for managing postoperative chylothorax. These include conservative treatment, interventional procedures and surgical re-exploration for the closure of leak or duct ligation. Successful management is often achieved using a combination of these approaches. Intraoperative prophylactic thoracic duct ligation has been suggested to reduce the incidence of chylothorax following highrisk procedures.
\end{abstract}

Keywords: Chylothorax; thoracic duct; postoperative; duct embolization; duct ligation

Received: 21 July 2020; Accepted: 22 September 2020; Published: 10 July 2021.

doi: 10.21037/shc-2019-amp-07

View this article at: http://dx.doi.org/10.21037/shc-2019-amp-07

\section{Introduction}

Chyle refers to a milky fluid formed in the lacteal system in the intestine. In Latin, chyle means juice. It constitutes mainly of triglycerides, proteins, immunoglobulin and lymphocytes. It is therefore bacteriostatic. The thoracic duct transports up to $2.5 \mathrm{~L}$ of chyle a daily (1). The flow of chyle is unidirectional due to the presence of valves in the ductal system. The actual flow is aided by the intraabdominal and intra-thoracic pressures as well as changes in the muscle tone of the duct wall itself (2) and pulsation from adjacent blood vessels.

Chylothorax refers to the accumulation of chyle in the pleural space. It was first described by Bartolet in 1633 (3). Chylothorax is a rare cause of a pleural effusion. The differential diagnosis is therefore wide. Causes of chylothorax could be broadly divided into congenital, traumatic or neoplastic. The presence of a milky effusion is not always the result of a chylothorax. Cholesterol effusion due to chronic inflammatory disorders, such as tuberculosis or rheumatoid arthritis, could present as a pseudochylothorax (4).

Postoperative chylothorax results from injury to the thoracic duct or any of its tributaries leading to the leakage of chyle into the pleural space. This has been reported following several procedures including oesophageal $(5,6)$, pulmonary, mediastinal, neck or aortic surgery $(7)$. Postoperative chylothorax occurs in $0.25-3 \%$ of cases following pulmonary surgery $(7,8)$. Chylothorax following pulmonary resections is more likely to result from injury to the thoracic duct tributaries during mediastinal nodal dissection (9).

Injury to the thoracic duct causes large volumes of chyle 


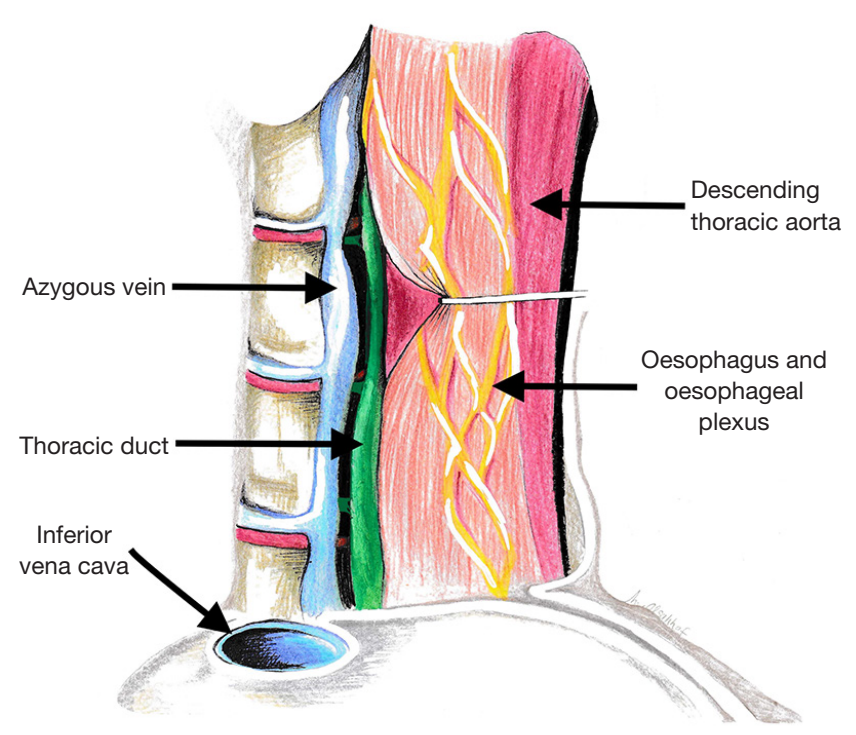

Figure 1 Aetiology of chylothorax.

to accumulate in the pleural space. Untreated, chylothorax has a reported mortality of up to $30 \%(10,11)$.

This chapter reviews the anatomy of the thoracic duct, pathophysiology, risks for developing postoperative chylothorax, presentation, diagnosis, management, as well as some intraoperative preventative measures.

\section{Anatomy of the thoracic duct}

Knowledge of the anatomy and possible variations in the course of the duct helps prevent inadvertent intraoperative injury. The thoracic duct originates in the abdomen. It arises from the cisterna chyli at the level of the second lumbar vertebra. Following this, it ascends to the posterior mediastinum of the thoracic cavity via the aortic hiatus in the diaphragm. At this level, it lies on the left side of the azygous vein, the right side of the descending aorta and behind the oesophagus. This segment of the duct is covered by mediastinal pleura (12). Then, it ascends through the right hemithorax to the level of the fifth vertebra where it crosses over to the opposite hemithorax. In the left chest, it ascends along the left side of the oesophagus, posterior to the aortic arch and the left subclavian artery. It terminates by draining into the venous system between the left subclavian and the internal jugular veins. There are multiple variations to the anatomy of the thoracic duct.

\section{Aetiology of chylothorax (Figure 1)}

The aetiology of chylothorax is broadly divided into three categories including congenital, traumatic and neoplastic causes. Up to $50 \%$ of chylous effusions are attributed to traumatic causes. Traumatic causes are further subdivided into iatrogenic and non-iatrogenic. Iatrogenic causes refer to those caused by surgical or medical interventions (5). Non-iatrogenic causes refer to those caused by blunt or penetrating traumatic injuries. Of all the traumatic causes of chylothorax, iatrogenic injuries are the commonest. They are approximately four times more common than noniatrogenic causes (13).

Traumatic iatrogenic chylothorax has been described following multiple thoracic interventions including thoracic and cardiac surgery $(14,15)$, lymph node dissection, oesophagectomies (16) and surgery on the thoracic aorta or the left subclavian artery. The reported incidence of chylothorax post thoracoscopic lung resection is $2.6 \%$ (17). Traumatic chylothorax could also be caused by neck dissection resulting in injury to the cervical part of the duct $(18,19)$. Trans-hiatal or thoracoscopic oesophagectomy is found to be the commonest cause of postoperative chylothorax following thoracic surgery. This may be due to dissection of the oesophagus where it is closest to the duct at the level of the arch of the azygous vein. Other interventions such as left-sided central line insertion, 
sclerotherapy for varices and angiography have also been described as possible causes of iatrogenic chylothorax (20).

\section{Presentation of postoperative chylothorax}

Chylothorax becomes more evident when patients start oral intake. The volume and characteristics of the chyle drained depend on the size and the cause of the leak. The symptoms depend on the volume of chylothorax and reflect the effects of the lost chyle constituents. As such, patients may present with breathlessness due to compression of the lung and mediastinal structures by a large pleural effusion. However; this is less common in postoperative scenarios as patients are more likely to still have chest tubes by the time the chylothorax is detected. The presence of chest drains aids earlier diagnosis and reduce the risk of developing compression related respiratory symptoms. Other effects of chylothorax include hyponatremia, hypocalcaemia, hypovolaemia and acidosis. Prolonged leakage of large volumes of chyle will lead to clinical decompensation. Malnutrition occurs due to loss of vitamins, fat and proteins. Immunosuppression occurs due to loss of immunoglobulins and $\mathrm{T}$ lymphocytes which impairs both humoral antigen response and cell-mediated immunity. If recognized late or managed poorly, postoperative chylothorax could have devastating consequences.

\section{Operative risk factors for developing chylothorax}

\section{Extent of resection}

Several reports in the literature document the extent of lung resection undertaken and the associated incidence of chyle leak. Chylothorax is seen in $0.25-1.28 \%$ post-lobectomy and in $0.37-0.7 \%$ post-pneumonectomy. There appears to be no significant predictor value for the extent of lung resection in causing chyle leak postoperatively $(7,21)$. Of all thoracic procedures, oesophagectomy seems to be the commonest cause of postoperative chylothorax (20).

\section{Mediastinal lymphadenectomy}

Akin et al. suggested a strong correlation between mediastinal lymphadenectomy and the development of chylothorax with an incidence of $1.9 \%$ (22). The incidence is higher in patients with pathological N2 disease (23). This may be due to the higher risk of injury to surrounding structures, including the thoracic duct or its tributaries, during dissection of enlarged, pathologically involved lymph nodes. Also, metastatic cancer in pathological nodes could increase the pressure in the lymphatic system leading to chyle leak.

\section{Side of procedure}

There is evidence to suggest a higher incidence of chylothorax following right-sided lung resections. Bryant et al. reviewed 41 cases of chylothorax post-lung resection and found that there is a statistically significant $(\mathrm{P}<001)$ higher incidence of chylothorax following radical rightsided lung resections (23). This may be because the volume of chyle draining from the left pleural space to right space is larger than that draining in the opposite direction.

\section{Variation in thoracic duct anatomy}

As mentioned earlier, the anatomical course of the thoracic duct can be variable. This may lead to inadvertent injury to the duct or its tributaries even if the site of surgical dissection appears away from the commoner anatomical variations.

\section{Diagnosis}

Postoperative chylothorax is rare. Delayed diagnosis or poor management will result in significant morbidity and mortality (11). Chyle is seen in the drain fluid in postoperative patients, mostly, after the commencement of oral intake. One must treat these cases with a high index of suspicion to enable early diagnosis. A large drain output is often associated with chylothorax although this could also be caused by extensive surgery or postoperative ooze etc.

Only $50 \%$ of cases of chylothorax have a classic milky appearance. This is because chyle could appear haemoserous or serous if there is an associated haemothorax or if the patient is fasting. Lab analysis is, therefore, necessary for confirmation of the diagnosis. The fluid should be sent for biochemical analysis as well as a gram stain. Chyle is bacteriostatic. It has a triglyceride level $>110 \mathrm{mg} / \mathrm{dL}$ (24). A triglyceride level of less than $50 \mathrm{mg} / \mathrm{dL}$ virtually excludes the diagnosis (25). A triglyceride value between 50 and $110 \mathrm{mg} / \mathrm{dL}$ is ambiguous. Therefore, in equivocal cases, chylomicrons should be measured using lipoprotein electrophoresis (26). The presence of chylomicrons confirms the diagnosis. Chyle also has a cholesterol to triglyceride ratio of less than 1 (27) and it has a lymphocyte count greater than $90 \%$.

Some factors including malnutrition and fasting should 
be considered when making a diagnosis of chylothorax. This is because these factors may lead to a triglyceride value lower than the traditional cut-off value used in excluding chylothorax (28).

Chest radiography and computerized tomography are of limited use in the diagnosis of postoperative chylothorax. This is because even if these investigations demonstrate a pleural effusion, their use does not help characterise the nature of this effusion.

Lymphangiography can confirm and locate the site of a leak in over $80 \%$ of cases (7). In addition, lymphangiography is associated with the closure of leak in up to $70 \%$ of cases in patients with a chyle output $<500 \mathrm{~mL} /$ day and in $35 \%$ of patients with a chyle output of $>500 \mathrm{~mL} /$ day. Overall; it has a $51 \%$ success rate in the closure of chyle leaks. This is found to be independent of the cause of duct injury or the time from injury to intervention (29).

Lymphoscintigraphy utilizes the absorption of watersoluble technicium-99 albumin solution into lymphatics to image the radiotracer. Its role is less established in small vessel leaks due to its water-soluble nature but it has been utilized successfully to identify chylothorax $(30,31)$.

\section{Management}

Due to the low incidence of postoperative chylothorax, there are no standardised guidelines for management. Management requires a multidisciplinary approach and includes conservative management, thoracic duct embolization, thoracic duct disruption and surgical intervention.

\section{Conservative management}

Refers to the non-interventional treatment of chylothorax. This is commenced at the outset of diagnosis and could continue for some time if the daily drainage is $<500 \mathrm{~mL} /$ day. Conservative management includes:

\section{Pleural drainage}

Intrapleural drainage is imperative to enable lung reexpansion, improve breathing and decrease pleural pressure on mediastinal structures. It also quantifies the daily drainage to help guide volume resuscitation to prevent hypovolaemia. The amount and the appearance of the fluid drained must be recorded accurately to guide decision making in the treatment of chylothorax. The chest drain should not be connected to suction to help reduce the leakage of chyle through the defect (9).

\section{Diet modification}

Reducing chyle flow is pivotal in reducing the overall complication profile and enabling spontaneous healing of the causative injury. The flow of chyle in the thoracic duct increases after meals especially those with high-fat content. Oral medium-chain triglyceride diet reduces the flow of lymph. Unlike long-chain triglycerides, which get absorbed in the intestinal lacteal and thoracic duct, the absorption of medium-chain triglycerides occurs via the portal vein (32). However; because any oral intake is known to stimulate chyle production, patients are often managed by stopping all oral intake and commencing total parenteral nutrition. Total parenteral nutrition is more effective in reducing the flow of chyle than a diet consisting of medium-chain triglycerides or low fat (33).

\section{Drug therapy}

Somatostatin and octreotide, a somatostatin analogue, are effective in enhancing spontaneous closure of the chylous fistula. It can be administered as a continuous infusion $(6 \mathrm{mg} /$ day) or subcutaneous injection (50 or $100 \mu \mathrm{g}$ every $8 \mathrm{~h}$ ). Bryant et al. had a $90 \%$ success rate in treating chylothorax following lung resection and mediastinal nodal dissection using a combination of diet modification and octreotide (23). Octreotide can also be an effective treatment following thoracic oesophagectomy for oesophageal cancer. Factors which may predict failure of treatment in these settings include large volume drain output of $>1 \mathrm{~L} /$ day (34).

\section{Pleurodesis}

Chemical pleurodesis may be considered to obliterate the pleural space. This could be used as part of the conservative management to minimize the need for surgical intervention $(22,35)$.

\section{Thoracic duct embolization/disruption}

In recent years, percutaneous duct embolization or needle disruption have been described in the treatment of high out-put chylothorax (36). These procedures have become valuable interventions for non-operative control of chyle leak. Thoracic duct embolization and disruption can result 
in up to $80 \%$ success in treating traumatic chylothorax (37). Different techniques have described the combination of microcoils and liquid embolic agents yielding a success rate as high as $91 \%$. Thoracic duct disruption causes thrombus formation as well as inflammation which leads to leak closure. Complications from these procedures have been reported and include peritonitis, bleeding, and pulmonary embolism $(38,39)$.

Targeted Sclerotherapy by direct puncture of the lymphatic leak site has been recently described to treat cases after failed thoracic duct embolization or disruption (40).

\section{Surgery}

There is much debate about the optimal timing of surgery with a lack of consensus guidelines. The treatment approach is mostly an institution or surgeon driven. Surgery was previously reserved for those who fail conservative approach. More recently, however; there has been a gradual shift towards early intervention $(41,42)$ with reports of up to $90 \%$ success rate with surgery.

The daily volume of chyle is an important factor to consider when deciding on the approach for treatment. It's advocated that early surgical intervention should be considered for those with high-volume output (43-45). The definition of what constitutes high output chyle leak varies in the literature with figures ranging from $>500-1,000 \mathrm{~mL} /$ day. A high output leak could be detected as early as in the first 12 hours post-surgery even before the commencement of oral intake (42). As such, an early high chyle output could be used as a predictor for the need for surgical intervention in the postoperative period. In cases of chylothorax postoesophagectomy, leaks are often large and patients are generally already debilitated and malnourished. Hence, in these cases, early intervention is recommended $(10,33)$.

Surgery is either aimed at direct repair of the leak or mass ligation of the duct. For mass ligation, the duct is usually targeted as it enters the right hemithorax through the aortic hiatus. This is performed either via open thoracotomy or using a minimally invasive approach such as robotic or video-assisted thoracoscopy. In current times, minimally invasive surgery is being utilized more frequently to treat postoperative chylothorax with good results $(46,47)$. The localization of the leak is achieved using pedal lymphangiography or by the administration of Intra-operative enteral cream with or without methylene blue via a nasogastric tube (48). If unable to identify the site of the leak intraoperatively, thoracic duct ligation is then considered to ensure sealing at the point of entry of the duct into the chest. This will ensure sealing of the duct and its branches.

\section{Mass ligation (upstream ligature)}

The supradiaphragmatic position of the thoracic duct on the right is the favoured site for ligation because of its more consistent anatomy.

The duct is identified between the azygous vein and the descending thoracic aorta. The oesophagus is retracted anteriorly and the diaphragm inferiorly to help identify the hiatus. The duct and surrounding tissue are lifted using a right-angle clamp and a thick pledgeted non-absorbable suture is used in a figure of 8 to tie off this tissue for direct closure. Large metal clips could be applied instead. Unidentified leak site, anatomical variations of the duct and cases of accessory ducts could potentially all lead to surgical failure $(49,50)$. These cases could, therefore, be treated with mass ligation of the thoracic duct to ensure successful surgical closure. One must observe the site of ligation for a few minutes intraoperatively to ensure sealing has been successful before ending the procedure. Thoracic duct ligation is $95 \%$ successful in postoperative chylothoraxes (45).

Postoperative drainage must be recorded accurately to document not only the drain output but also the nature of the fluid drained. Chest drains can be removed once a fullfat diet has been resumed with no evidence of recurrent chyle leak.

\section{Pleuroperitoneal shunts}

Pleuroperitoneal shunts are rarely used in postoperative chylothorax. They have been described as a last resort in refractory chylothorax after failed surgical duct ligation. Two different types of shunts have been used to treat chylothorax. These include a Denver pleuroperitoneal shunt which is an active shunt and a LeVeen pleuroperitoneal shunt which is passive (51). Shunts are placed in the chest with a catheter transporting chyle from the chest to the peritoneal cavity. Complications of pleuroperitoneal shunts include shunt occlusion, pneumoperitoneum, infection and shunt migration (52).

\section{Prevention of postoperative chylothorax}

Prophylactic thoracic duct ligation during oesophagectomy is a controversial topic. In a randomised controlled trial of 
653 patients who underwent transthoracic oesophagectomy, chylothorax was diagnosed in $1.2 \%$. Of these, $0.3 \%$ were seen in the group that underwent intraoperative thoracic duct ligation vs. $2.1 \%$ in the group that did not. This confirms that intraoperative thoracic duct ligation is safe and effective (53). Another approach that has been described to help prevent ductal injury during surgery includes the use of cream given before oesophageal resection to help improve thoracic duct visualisation intraoperatively. This is done in an attempt to prevent inadvertent or unrecognised intraoperative thoracic duct trauma and hence reduces the risk of developing postoperative chylothorax (48).

Prophylactic video-assisted thoracoscopic duct ligation during thoracoscopic oesophagectomy has also been attempted and has shown a statistically significant reduction in patients who underwent preventative ligation compared to those who did not (20).

\section{Conclusions}

Despite the low incidence of chylothorax following thoracic surgery, it is associated with significant morbidity and has a mortality of up to $30 \%$. Surgeons faced with the challenges of postoperative chylothorax must have a good understanding of the anatomy, the anatomical variations of the thoracic duct and the pathophysiology. Early diagnosis and aggressive management should be implemented to minimise adverse consequences. Chronic chylothorax complications including malnutrition, metabolic derangements and immunosuppression. A multi-disciplinary team approach is necessary to improve outcomes. Advancements in interventional radiology procedures have changed the previously held management algorithms with good outcomes. Surgery remains the mainstay for successful treatment in high-volume postoperative chylothorax. It is worth noting some of the preventative techniques which could reduce the risk of postoperative chylothorax, especially while undertaking procedures deemed high-risk for the development of postoperative chylothorax.

\section{Acknowledgments}

Funding: None.

\section{Footnote}

Provenance and Peer Review: This article was commissioned by the Guest Editor (David Waller) for the series
"Complications of Thoracic Surgery - aetiology, management and prevention" published in Shanghai Chest. The article has undergone external peer review.

Conflicts of Interest: The author has completed the ICMJE uniform disclosure form (available at http:// dx.doi.org/10.21037/shc-2019-amp-07). The series "Complications of Thoracic Surgery - aetiology, management and prevention" was commissioned by the editorial office without any funding or sponsorship. The author has no other conflicts of interest to declare.

Ethical Statement: The author is accountable for all aspects of the work in ensuring that questions related to the accuracy or integrity of any part of the work are appropriately investigated and resolved.

Open Access Statement: This is an Open Access article distributed in accordance with the Creative Commons Attribution-NonCommercial-NoDerivs 4.0 International License (CC BY-NC-ND 4.0), which permits the noncommercial replication and distribution of the article with the strict proviso that no changes or edits are made and the original work is properly cited (including links to both the formal publication through the relevant DOI and the license). See: https://creativecommons.org/licenses/by-nc-nd/4.0/.

\section{References}

1. Misthos P, Kanakis MA, Lioulias AG. Chylothorax complicating thoracic surgery: conservative or early surgical management? Updates Surg 2012;64:5-11.

2. Paes ML, Powell H. Chylothorax: an update. Br J Hosp Med 1994;51:482-90.

3. Bower GC. Chylothorax: observations in 20 cases. Dis Chest 1964;46:464-8.

4. Lama A, Ferreiro L, Toubes ME, et al. Characteristics of patients with pseudochylothorax-a systematic review. J Thorac Dis 2016;8:2093-101.

5. Doerr CH, Allen MS, Nichols FC 3rd, et al. Etiology of chylothorax in 203 patients. Mayo Clin Proc 2005;80:867-70.

6. Shah RD, Luketich JD, Schuchert MJ, et al. Postesophagectomy chylothorax: incidence, risk factors, and outcomes. Ann Thorac Surg 2012;93:897-903; discussion 903-4.

7. Cerfolio RJ, Allen MS, Deschamps C, et al. Postoperative chylothorax. J Thorac Cardiovasc Surg 1996;112:1361-6. 
8. Takuwa T, Yoshida J, Ono S, et al. Low-fat diet management strategy for chylothorax after pulmonary resection and lymph node dissection for primary lung cancer. J Thorac Cardiovasc Surg 2013;146:571-4.

9. Chalret du Rieu M, Baulieux J, Rode A, et al. Management of postoperative chylothorax. J Visc Surg 2011;148:e34652. Erratum in: J Visc Surg. 2012 Feb;149(1):e80. Baulieux, J [added]; Rhode, A [added].

10. Wemyss-Holden SA, Launois B, Maddern GJ. Management of thoracic duct injuries after oesophagectomy. Br J Surg 2001;88:1442-8.

11. Martucci N, Tracey M, Rocco G. Postoperative Chylothorax. Thorac Surg Clin 2015;25:523-8.

12. Al-Sahaf M, Witzke H, Waller D. Pleura and thoracic sympathetic trunk. In: Brennan P, Standring Susan, Wiseman Sam. editors. Gray's Surgical Anatomy. Elsevier, 2019:331-5.

13. Breaux JR, Marks C. Chylothorax causing reversible T-cell depletion. J Trauma 1988;28:705-7.

14. Migliori C, Boroni G, Milianti S, et al. Chylothorax. Minerva Pediatr 2010;62:89-91.

15. Waikar HD, Kamalaneson P, Mohamad Zamri MS, et al. Chylothorax after off-pump coronary artery bypass graft surgery: Management strategy. Ann Card Anaesth 2018;21:300-3.

16. Bolger C, Walsh TN, Tanner WA, et al. Chylothorax after oesophagectomy. Br J Surg 1991;78:587-8.

17. Liu CY, Hsu PK, Huang CS, et al. Chylothorax complicating video-assisted thoracoscopic surgery for nonsmall cell lung cancer. World J Surg 2014;38:2875-81.

18. Merrigan BA, Winter DC, O'Sullivan GC. Chylothorax. Br J Surg 1997;84:15-20.

19. Pillay TG, Singh B. A review of traumatic chylothorax. Injury 2016;47:545-50.

20. Guo W, Zhao YP, Jiang YG, et al. Prevention of postoperative chylothorax with thoracic duct ligation during video-assisted thoracoscopic esophagectomy for cancer. Surg Endosc 2012;26:1332-6.

21. Kutlu CA, Sayar A, Olgac G, et al. Chylothorax: a complication following lung resection in patients with NSCLC - chylothorax following lung resection. Thorac Cardiovasc Surg 2003;51:342-5.

22. Akin H, Olcmen A, Isgorucu O, et al. Approach to patients with chylothorax complicating pulmonary resection. Thorac Cardiovasc Surg 2012;60:135-9.

23. Bryant AS, Minnich DJ, Wei B, et al. The incidence and management of postoperative chylothorax after pulmonary resection and thoracic mediastinal lymph node dissection.
Ann Thorac Surg 2014;98:232-5; discussion 235-7.

24. Romero Candeira S, Navarro Téllez P, Trigo Maestro C, et al. Usefulness of the determination of lipids parameters in pleural effusions. Med Clin (Barc) 1989;92:450-3.

25. Skouras V, Kalomenidis I. Chylothorax: diagnostic approach. Curr Opin Pulm Med 2010;16:387-93.

26. Huggins JT. Chylothorax and cholesterol pleural effusion. Semin Respir Crit Care Med 2010;31:743-50.

27. Staats BA, Ellefson RD, Budahn LL, et al. The lipoprotein profile of chylous and nonchylous pleural effusions. Mayo Clin Proc 1980;55:700-4.

28. Maldonado F, Hawkins FJ, Daniels CE, et al. Pleural fluid characteristics of chylothorax. Mayo Clin Proc 2009;84:129-33.

29. Alejandre-Lafont E, Krompiec C, Rau WS, et al. Effectiveness of therapeutic lymphography on lymphatic leakage. Acta Radiol 2011;52:305-11.

30. Sugiura K, Tanabe Y, Ogawa T, et al. Localization of chyle leakage site in postoperative chylothorax by oral administration of I-123 BMIPP. Ann Nucl Med 2005;19:597-601.

31. Yoshida RY, Kariya S, Ha-Kawa S, et al. Lymphoscintigraphy for Imaging of the Lymphatic Flow Disorders. Tech Vasc Interv Radiol 2016;19:273-6.

32. Bloom B, Chaikoff IL, Reinhardt. Intestinal lymph as pathway for transport of absorbed fatty acids of different chain lengths. Am J Physiol 1951;166:451-5.

33. Nair SK, Petko M, Hayward MP. Aetiology and management of chylothorax in adults. Eur J Cardiothorac Surg 2007;32:362-9.

34. Fujita T, Daiko H. Efficacy and predictor of octreotide treatment for postoperative chylothorax after thoracic esophagectomy. World J Surg 2014;38:2039-45.

35. Cho HJ, Kim DK, Lee GD, et al. Chylothorax complicating pulmonary resection for lung cancer: effective management and pleurodesis. Ann Thorac Surg 2014;97:408-13.

36. Binkert CA, Yucel EK, Davison BD, et al. Percutaneous treatment of high-output chylothorax with embolization or needle disruption technique. J Vasc Interv Radiol 2005;16:1257-62.

37. Pamarthi V, Stecker MS, Schenker MP, et al. Thoracic duct embolization and disruption for treatment of chylous effusions: experience with 105 patients. J Vasc Interv Radiol 2014;25:1398-404.

38. Chen E, Itkin M. Thoracic duct embolization for chylous leaks. Semin Intervent Radiol 2011;28:63-74.

39. Lee EW, Shin JH, Ko HK, et al. Lymphangiography to 
treat postoperative lymphatic leakage: a technical review. Korean J Radiol 2014;15:724-32.

40. Takahashi M, Inoue M, Wada T, et al. Chylothorax treated with targeted sclerotherapy by direct puncture of the lymphatic leakage site. Radiol Case Rep 2020;15:1398-402.

41. Merigliano S, Molena D, Ruol A, et al. Chylothorax complicating esophagectomy for cancer: a plea for early thoracic duct ligation. J Thorac Cardiovasc Surg 2000;119:453-7.

42. Uchida S, Suzuki K, Hattori A, et al. Surgical intervention strategy for postoperative chylothorax after lung resection. Surg Today 2016;46:197-202.

43. Reisenauer JS, Puig CA, Reisenauer CJ, et al. Treatment of Postsurgical Chylothorax. Ann Thorac Surg 2018;105:254-62.

44. Zabeck H, Muley T, Dienemann H, et al. Management of chylothorax in adults: when is surgery indicated? Thorac Cardiovasc Surg 2011;59:243-6.

45. Paul S, Altorki NK, Port JL, et al. Surgical management of chylothorax. Thorac Cardiovasc Surg 2009;57:226-8.

46. Thompson KJ, Kernstine KH, Grannis FW Jr, et al. Treatment of chylothorax by robotic thoracic duct ligation.

doi: 10.21037/shc-2019-amp-07

Cite this article as: Al-Sahaf M. Postoperative chylothorax. Shanghai Chest 2021;5:28.
Ann Thorac Surg 2008;85:334-6.

47. Kent RB, Pinson TW. Thoracoscopic ligation of the thoracic duct. Surg Endosc 1993;7:52-3

48. Shackcloth MJ, Poullis M, Lu J, et al. Preventing of chylothorax after oesophagectomy by routine preoperative administration of oral cream. Eur J Cardiothorac Surg 2001;20:1035-6.

49. Ahmed SU, Sancheti MS, Pickens A. Thoracoscopic Thoracic Duct Ligation. Oper Tech Thorac Cardiovasc Surg 2012;17:292-301.

50. Schild HH, Strassburg CP, Welz A, et al. Treatment options in patients with chylothorax. Dtsch Arztebl Int 2013;110:819-26.

51. Gupta D, Ross K, Piacentino V 3rd, et al. Use of LeVeen pleuroperitoneal shunt for refractory high-volume chylothorax. Ann Thorac Surg 2004;78:e9-12.

52. Foroulis CN, Desimonas NA. Massive pneumoperitoneum: a late complication of the Denver pleuroperitoneal shunt. Ann Thorac Surg 2005;80:e13.

53. Lai FC, Chen L, Tu YR, et al. Prevention of chylothorax complicating extensive esophageal resection by mass ligation of thoracic duct: a random control study. Ann Thorac Surg 2011;91:1770-4. 